\title{
IMPASSES DAACCOUNTABILITY:
}

\section{DILEMAS E ALTERNATIVAS DAREPRESENTAÇÃO POLÍTICA ${ }^{1}$}

\author{
Luís Felipe Miguel
}

\begin{abstract}
RESUMO
Um elemento crucial das democracias eleitorais é a accountability, que garantiria o vínculo entre representantes e representados. Mas as esperanças depositadas nela não encontram mais do que uma pálida efetivação na prática política. A capacidade de supervisão dos constituintes sobre seus representantes é reduzida, devido a fatores que incluem a complexidade das questões públicas, o fraco incentivo à qualificação política e o controle sobre a agenda. Diante dessa situação, surgem propostas de transformação radical dos mecanismos representativos, que resgatam a idéia de "representação descritiva" e enfraquecem ou mesmo abolem a accountability. É o caso, notadamente, da representação de grupos e da substituição das eleições por sorteios. Embora prescindindo de instrumentos formais de responsividade dos governantes em relação aos governados, as formas propostas gerariam um corpo de representantes mais assemelhado ao conjunto da população e ampliariam a rotatividade nos cargos decisórios. O presente artigo analisa as propostas de representação descritiva sob o ângulo da relação entre representantes e representados. Embora muitas vezes padeçam de sérias fragilidades e pareçam inviáveis para implementação efetiva, essas propostas incorporam críticas importantes e que merecem ser levadas em consideração, a respeito do funcionamento da representação eleitoral e, em particular, da accountability.
\end{abstract}

PALAVRAS-CHAVE: representação política; democracia; accountability; democracia radical.

\section{INTRODUÇÃO}

Onde quer que situemos o início da busca por uma ciência da política - em Aristóteles, em Maquiavel ou em Hobbes, para citar apenas três precursores comumente considerados -, um tema central é a constituição e a manutenção do poder político. Conforme vai-se desenvolvendo o esforço de construção do conhecimento sobre a política, antes e depois da emergência da Ciência Política

\footnotetext{
${ }^{1}$ Este texto inclui resultados iniciais da pesquisa "Modelos alternativos de representação política”, apoiada pelo Conselho Nacional de Desenvolvimento Científico e Tecnológico (CNPq) com uma bolsa de Produtividade em Pesquisa. Uma versão inicial foi apresentada no Grupo de Trabalho "Controles democráticos e cidadania”, no $27^{\circ}$ Encontro Anual da Associação Nacional de Pesquisa e Pósgraduação em Ciências Sociais, realizado em Caxambu (MG), entre 21 e 25 de outubro de 2003. Agradeço as críticas e sugestões de Fábio Wanderley Reis, Paulo D’Ávila Filho, Cláudio Gonçalves Couto, Fernando LattmanWeltman e demais participantes do grupo. Também agradeço a leitura atenta e os comentários de Regina Dalcastagnè. Os erros e omissões, como de praxe, continuam sendo de minha inteira responsabilidade.
}

em sua feição contemporânea, esse tema desdobra-se em discussões sobre o problema da "obrigação política”, tão caro à tradição liberal²; sobre a "legitimidade" da dominação, na célebre formulação weberiana; sobre a "hegemonia”, que se tornou uma das grandes preocupações do pensamento marxista (e cuja referência crucial é, evidentemente, Gramsci, 2000 [1932-1934]); sobre a "governabilidade", conceito de enorme penetração, que tem sua origem no pensamento mais conservador (CROZIER, HUNTINGTON \& WATANUKI, 1975) e tantas outras.

É legítimo afirmar que, em grande parte da Ciência Política contemporânea, o tema da formação e da manutenção do poder se transmuta no tema da organização democrática. A partir da II Guerra Mundial, num processo contínuo, a democracia vem ganhando legitimidade universal. Nos países do Ocidente, é o único regime político capaz de garantir a aceitação dos governados. Em todo o mundo, os mais diferentes regimes busca-

\footnotetext{
2 Para uma resenha crítica, ver Pateman (1985).
} 
ram adaptar o rótulo de "democrático" para si próprios - gerando uma miríade de democracias adjetivadas, das "democracias populares" do Leste europeu à “democracia islâmica” da Líbia e do Irã - ou, ao menos, afirmavam ser etapas necessárias para a edificação da democracia, como as ditaduras de segurança nacional na América do Sul.

Assim, no campo da teoria política, ao menos a partir da segunda metade do século XX, a teoria da democracia torna-se a preocupação dominante (secundada pela discussão sobre a justiça). A democracia também é uma das questões centrais nos estudos empíricos da Ciência Política, quer de maneira direta, quer indireta (estudos sobre eleições, sobre processos decisórios, sobre elites). De maneira talvez um pouco simplificada, mas ainda assim sustentável, pode-se dizer que a democracia é, já há algumas décadas, o horizonte normativo - explicitado ou implícito - de quase toda a Ciência Política.

Falou-se há pouco das "democracias adjetivadas”. Há, em contraposição a elas, uma democracia não-adjetivada, o regime político que é geralmente aceito como democrático, pelo senso comum e também pelas Ciências Sociais. No entanto, tal regime afasta-se, e muito, do sentido etimológico da democracia e das características da democracia clássica grega, da qual herdamos não apenas a palavra como boa parte do imaginário associado a ela. Por um lado, o povo não exerce o poder, a não ser, no máximo, de uma forma bastante mediada. Por outro lado, as instituições centrais das democracias contemporâneas - o processo eleitoral e o parlamento como colégio de representantes - são estranhas ao experimento grego. Até o século XVIII, eram consideradas intrinsecamente aristocráticas ${ }^{3}$.

Nossas democracias são, portanto, democracias representativas e constatar a impossibilidade da democracia direta nas sociedades contemporâneas é algo banal. Nossos estados são muito extensos para que todos reúnam-se e muito populosos para que se possa imaginar um diálogo que incorpore cada um de seus cidadãos. As ques-

\footnotetext{
3 Segundo Montesquieu (1951 [1748], p. 242), “o sufrágio por sorteio está na natureza da democracia; o sufrágio por eleição está na da aristocracia”. O mesmo aparece em Rousseau (1964 [1757]). Sobre o ponto, ver Manin (1997).
}

tões políticas são complexas demais para que dispensemos a especialização dos governantes e, por sua vez, os afazeres privados absorvem demais cada um de nós, reduzindo ao mínimo o tempo para a participação política. A incorporação de tantos grupos ao demos - trabalhadores, mulheres, imigrantes - ampliou a profundidade das clivagens em seu seio, tornando indispensável a existência de alguma forma de mediação. Enfim, seja qual for a justificativa, não resta dúvida de que a representação política é incontornável para qualquer tentativa de construção da democracia nos estados nacionais contemporâneos.

Mas a familiaridade com que a expressão "democracia representativa” é recebida não deve obscurecer o fato de que ela encerra uma contradição. Trata-se de um governo do povo no qual o povo não estará presente no processo de tomada de decisões. De maneira um pouco mais sistemática, é possível observar que a construção de uma ordem democrática, qualquer que seja ela, coloca uma série de desafios - a relação entre as preferências individuais e uma hipotética "vontade coletiva”, isto é, como permitir a livre expressão dos interesses em conflito e ainda assim manter uma unidade mínima, sem a qual nenhuma sociedade pode existir; a capacidade diferenciada que os indivíduos têm de determinar seus próprios interesses, de acordo com os recursos cognitivos de que dispõem, ou seja, o fato de que a igualdade formal de acesso às decisões não resolve os problemas colocados pelas desigualdades reais que existem na sociedade; ou, ainda, a possibilidade de manipulação da determinação da "vontade coletiva", por meio do uso estratégico das normas de agregação de preferências.

São desafios que estão presentes mesmo em situação de "democracia direta". Mas a necessidade de representação política coloca um novo e gigantesco conjunto de problemas, tão ou mais grave que o primeiro. São ao menos três problemas fundamentais, estreitamente ligados entre si:

(1) a separação entre governantes e governados, isto é, o fato de que as decisões políticas são tomadas de fato por um pequeno grupo e não pela massa dos que serão submetidos a elas;

(2) a formação de uma elite política distanciada da massa da população, como conseqüência da especialização funcional acima mencionada. $\mathrm{O}$ "princípio da rotação", crucial nas democracias da Antigüidade - governar e ser governado, 
alternadamente -, não se aplica, uma vez que o grupo governante tende a exercer permanentemente $\mathrm{o}$ poder $\mathrm{e}$

(3) a ruptura do vínculo entre a vontade dos representados e a vontade dos representantes, o que se deve tanto ao fato de que os governantes tendem a possuir características sociais distintas das dos governados, quanto a mecanismos intrínsecos à diferenciação funcional, que agem mesmo na ausência da desigualdade na origem social, conforme Michels (1982 [1914]) tentou demonstrar já no início do século $\mathrm{XX}^{4}$.

A resposta que as instituições democráticas tendem a dar para os três problemas é a mesma: accountability. Isso se refere ao controle que os poderes estabelecidos exercem uns sobre os outros (accountability horizontal), mas, sobretudo, à necessidade que os representantes têm de prestar contas e submeter-se ao veredicto da população (accountability vertical) ${ }^{5}$. O ponto culminante da accountability vertical é a eleição - que, assim, ocupa a posição central nas democracias representativas, efetivando os dois mecanismos centrais da representação política democrática, que são a autorização, pela qual o titular da soberania (o povo) delega capacidade decisória a um grupo de pessoas, e a própria accountability.

As esperanças depositadas na accountability (vertical), no entanto, não encontram mais do que uma pálida efetivação na prática política. A capacidade de supervisão dos constituintes sobre seus representantes é reduzida, devido a fatores que incluem a complexidade das questões públicas, o

\footnotetext{
4 Em que pesem as simplificações, o determinismo e o tom demasiadamente peremptório, o livro fornece pistas valiosas para a compreensão dos problemas da representação política.

5 Peruzzotti e Smulovitz (2001) apresentam um tipo adicional de accountability, que denominam "social” e que seria exercido pelos meios de comunicação e por organizações não-governamentais (ONGs). Falta a essa dimensão, porém, a capacidade de aplicação de sanções; suas advertências e denúncias ganham efetividade apenas quando sensibilizam algum dos poderes constituídos, em especial o Judiciário (accountability horizontal) ou o eleitorado (accountability vertical). Julgo que é relevante entender o papel desempenhado pelos meios de comunicação e pelas ONGs no funcionamento das democracias representativas contemporâneas, mas dar a elas o status de uma terceira dimensão da accountability é injustificado.
}

fraco incentivo à qualificação política e o controle sobre a agenda. Nas últimas décadas, na maior parte dos países de democracia concorrencial, isso levou ao aumento do desencanto com os mecanismos representativos, sinalizado pelo aumento dos índices de abstenção eleitoral, pela erosão das lealdades partidárias e por manifestações de alienação.

Na primeira seção do texto, trato brevemente dos conceitos básicos para a discussão, como "representação" e "accountability”. Em seguida, apresento uma síntese dos estudos que apontam uma crise da representação ou da democracia nos países ocidentais, tanto os produzidos nos anos 1970, focados no problema da "governabilidade", quanto os mais recentes, publicados a partir dos anos 1990, que evidenciam o descrédito generalizado das instituições representativas entre os cidadãos comuns. Por fim, faço um balanço de propostas de transformação radical dos mecanismos representativos - em especial as que envolvem cotas eleitorais e sorteios -, ainda que ao preço de uma redução significativa da accountability.

\section{REPRESENTAÇÃO, RESPONSIVIDADE E ACCOUNTABILITY: CONCEITOS}

É praticamente um lugar-comum observar que accountability não possui tradução precisa para o português (e para outras línguas neolatinas) e, daí, extrair conjecturas sobre a qualidade de nossas democracias em comparação com as anglo-saxãs. O vocabulário da Ciência Política em língua portuguesa no Brasil, porém, possui o vocábulo "responsividade”, que ainda não está dicionarizado - tanto o Aurélio quanto o Houaiss registram apenas o adjetivo "responsivo" - mas encontra razoável curso nos escritos da área.

"Responsividade", entretanto, corresponde mais de perto ao inglês responsiveness, um conceito que está muito próximo, mas pode ser distinguido do de accountability ${ }^{6}$. A accountability diz respeito à capacidade que os constituintes têm de impor sanções aos governantes, notadamente reconduzindo ao cargo aqueles que se desincumbem bem de sua missão e destituindo os que possuem desempenho insatisfatório. Inclui a prestação de contas dos detentores de mandato e

6 Para a distinção accountability-responsividade, ver Manin, Przeworski e Stokes (1999, p. 9-10). 
o veredicto popular sobre essa prestação de contas. É algo que depende de mecanismos institucionais, sobretudo da existência de eleições competitivas periódicas, e que é exercido pelo povo $^{7}$. Já a responsividade refere-se à sensibilidade dos representantes à vontade dos representados; ou, dito de outra forma, à disposição dos governos de adotarem as políticas preferidas por seus governados.

À primeira vista, a distinção entre os dois conceitos é inóxia, já que a disposição dos representantes para respeitar as preferências dos constituintes (responsividade) depende da possibilidade que estes dispõem de premiar ou punir o comportamento dos tomadores de decisão (accountability). Trata-se de algo que está na base da construção das instituições dos regimes constitucionais modernos: não confiar na bondade dos governantes e, ao contrário, estabelecer um sistema de controles sociais sobre eles, tanto horizontais (divisão de poderes) quanto verticais (eleições periódicas). Mas a diferenciação entre os conceitos ganha maior utilidade - como será visto adiante - quando entram em cena propostas de ampliação da responsividade por meio de mecanismos que minimizam ou ignoram a accountability.

Nos estudos sobre democracia, a accountability ganha destaque por prometer um grau razoavelmente alto de controle do povo sobre os detentores do poder político, mas de uma forma exeqüível em sociedades populosas, extensas, complexas e especializadas como as contemporâneas. Ela apresenta um modelo mais sofisticado e atraente das relações entre representantes e representados do que as visões antitéticas do “mandato livre” e do "mandato imperativo".

Uma visão ingênua da representação política tende a considerar o representante como delegado de seus constituintes, cabendo-lhe apenas expressar, nos fóruns decisórios, a vontade majoritária de sua base. É a idéia de "mandato imperativo”, que, no limite, reduz o representante à posição de um emissário. Quando muito, ele poderia negociar soluções de compromisso, que, no entanto, precisariam ser referendadas pelos repre-

7 É curioso observar que se afirma que "o governo é accountable", mas evidentemente o exercício da accountability, no sentido apresentado aqui, pertence aos governados. sentados - como costuma ocorrer na representação sindical. No primeiro caso, o representanteemissário cumpre função mecânica e, em rigor, com o avanço das tecnologias de comunicação, chega a ser dispensável. No segundo, o representante-negociador retém recursos de poder importantes, sobretudo na medida em que combina capacidade de interlocução (externa) com liderança (interna), mas o processo decisório torna-se excessivamente moroso, exigindo múltiplas rodadas de negociação e de assembléias de base. Não é um modelo viável para a representação multifuncional, em caráter permanente, nas complexas sociedades contemporâneas.

Em oposição ao mandato imperativo, há a idéia de "mandato livre", que triunfou nas democracias representativas e que foi formulada com clareza exemplar na segunda metade do século XVIII, por Edmund Burke (1942 [1774]). No famoso "Discurso aos eleitores de Bristol”, o pensador inglês alinhou dois argumentos principais para justificar a autonomia dos representantes em relação a seus eleitores. O primeiro diz respeito à natureza da representação: o deputado representa a nação, não seu distrito em particular, muito menos só aqueles que sufragaram seu nome. O parlamento, diz ele, não é "um congresso de embaixadores que defendem interesses distintos e hostis”, mas a "assembléia deliberante de uma nação, com um interesse: o da totalidade” (idem, p. 312). O segundo argumento está ligado à competência. Além de serem escolhidos por suas qualidades distintivas, os deputados são colocados em uma posição que lhes permite compreender melhor as questões públicas, graças às informações a que têm acesso, às discussões no próprio parlamento e à especialização na tarefa legislativa. Burke enfatiza que o legislador não age com base na vontade, mas na razão - uma resposta a Rousseau que, anos antes, n'O contrato social, escrevera que a representação política era inadequada porque não é possível representar a vontade.

A doutrina burkeana permite responder à célebre crítica platônica ao governo popular, garantindo a expertise dos tomadores de decisão. Compatibiliza a democracia com a "liberdade dos modernos”, focada na vida privada, própria do liberalismo, que Benjamin Constant exaltava; graças à divisão do trabalho político, a maior parte da população pode (e deve) dedicar-se quase exclusivamente a seus assuntos pessoais, enquanto a 
minoria cuida dos assuntos de governo. Especialização e expertise, aliás, são duas faces de uma só moeda: uma leva à outra.

No entanto, o mandato livre que Burke preconiza não concede nenhum espaço à interlocução dos representantes com os representados; a estes últimos resta um papel predominantemente passivo. É possível ver, então, a accountability como uma espécie de "termo médio" entre o mandato livre e o mandato imperativo ${ }^{8}$. O representante não está preso às preferências expressas de seus constituintes, mas idealmente deve decidir da forma que eles decidiriam caso dispusessem das condições - tempo, informação, preparo - para deliberar. Esse vínculo hipotético é resgatável a qualquer momento, já que o mandatário deve estar pronto para responder aos questionamentos do público. E é o público quem decide o quão convincente foram suas explicações, pronunciandose nas eleições seguintes.

Trata-se de uma descrição engenhosa do funcionamento da accountability, mas é necessário abordar com maior cautela os diversos obstáculos à sua efetivação. O mais crucial deles está ligado ao fato de que a representação política nas sociedades modernas é multifuncional, ou seja, o mandato concedido, tanto no poder Executivo quanto no poder Legislativo, abrange uma quantidade indeterminada de questões. O mandatário possui poder de decisão sobre os temas mais diversos e, tipicamente, ao longo de seu termo, participará de centenas de diferentes processos deliberativos. Os custos de informação para os eleitores tornam-se altos, sobretudo porque, por definição, eles podem dedicar às questões públicas apenas uma pequena parcela de seu tempo e de sua atenção.

A multifuncionalidade da representação implica múltiplas prestações de conta; o eleitor deve não apenas ser capaz de acompanhá-las - na medida de seu interesse - como dar a cada uma seu justo peso no momento de produzir uma avaliação global do desempenho do governante. É freqüente, então, a adoção de estratégias de redução do significado da accountability, transformando a interlocução sobre as alternativas políticas em mera avaliação impressionista do impacto da ação

8 É a posição que transparece no clássico estudo de Pitkin (1967). governamental sobre a vida de cada indivíduo, como faz Downs (1957). Ou, então, limitando a accountability a formas de controle sobre a corrupção, exilando de vez a apreciação de políticas substantivas, o que aparece, por exemplo, em documentos do Banco Mundial (WORLD BANK, 1999) ou influenciados por sua perspectiva (SHAH, s/d; AFONSO, 1999).

São estratégias que tornam mais fácil a efetivação da accountability, mas ao preço de rebaixar o sentido da democracia, na medida em que abrem mão da idéia de governo popular. Caso este valor seja resgatado, as exigências tornam-se muito maiores. O bom funcionamento da accountability vertical dependerá da existência institucional de sanções efetivas sobre os representantes, da provisão de informação adequada e plural (não apenas sobre a atuação dos governantes, mas sobre o mundo social de modo geral) e do interesse pela política disseminado nos diferentes grupos da população.

Atualmente, os regimes considerados democráticos garantem sanções de tipo eleitoral para os governantes, mas falham, em maior ou menor grau, nos demais quesitos. O pluralismo dos meios de informação é limitado, seja pelos constrangimentos profissionais, seja pela pressão uniformizadora da concorrência mercantil; ou, ainda mais importante, devido aos interesses comuns dos proprietários das empresas de comunicação de massa, que, aliás, formam um mercado cada vez mais concentrado (BAGDIKIAN, 1997; MCCHESNEY, 1999). Vários indicadores - alguns dos quais serão discutidos na próxima seção mostram que o interesse pela política, por sua vez, é em geral baixo. Mais grave ainda, é distribuído de modo muito desigual; via de regra, pessoas pertencentes aos grupos de menor poder político, como trabalhadores, mulheres ou minorias étnicas, são também as que revelam menor interesse pela política (demonstrando que o interesse é, ao menos em parte, função das oportunidades de participação efetiva abertas pelo sistema político).

Cabe acrescentar um último critério para o bom funcionamento da accountability: os representantes devem ter poder efetivo para a implantação das políticas que preferem. O sentido do controle popular fica comprometido quando parte significativa das decisões é determinada por entidades externas, não sujeitas às sanções determinadas pelo eleitorado, sejam elas organismos multilaterais in- 
ternacionais (Organização das Nações Unidas, União Européia), agências de financiamento (Fundo Monetário Internacional, Banco Mundial), grupos econômicos privados com forte poder de chantagem (o "mercado") ou mesmo estados estrangeiros. Se tais organismos têm a capacidade de bloquear alternativas, resta pouco espaço para o exercício da soberania popular. É claro que o processo de globalização complicou o exercício da accountability, sobretudo nos países periféricos, que formam a ponta mais vulnerável da ordem globalista.

É importante destacar que a discussão aqui esboçada enfoca apenas a delegação de poder do povo a um conjunto de representantes eleitos. No entanto, esta é apenas uma dimensão da representação política, a mais evidente delas. Em sociedades extensas, populosas e complexas, mecanismos representativos estão necessariamente presentes também no debate público, que ocorre em primeiro lugar nos meios de comunicação de massa, e nos espaços de geração de preferências coletivas (MIGUEL, 2003).

\section{A CRISE DA REPRESENTAÇÃO}

A idéia de uma "crise da democracia" ganhou curso graças ao famoso relatório escrito por Samuel Huntington, Michel Crozier e Joji Watanuki à Comissão Trilateral, em meados dos anos 1970. Segundo eles, as democracias tornavam-se “ingovernáveis”, por motivos intrínsecos ao próprio método democrático. Ele levou à destruição de todas as hierarquias sociais, à ampliação das demandas de todos os setores da população, à geração de uma "cultura da contestação" e também à hiperpolitização da sociedade - um tema já antes explorado por Huntington (1975 [1968]), mas que então entendia como restrito a países periféricos em processo de modernização.

O relatório deve ser entendido dentro do contexto histórico em que foi escrito. Os anos 1960 presenciaram um crescimento expressivo da ativação política nos países centrais. Nos Estados Unidos, o movimento pelos direitos civis dos negros continuava em ascensão, assumindo formas cada vez mais impetuosas. A ele juntava-se a mobilização contra a Guerra do Vietnã. Em 1968 ocorreu, tanto na Europa quanto nos EUA, a explosão da rebeldia juvenil; mais grave ainda, em países como França e Itália, com a adesão de frações importantes da classe operária.
Parte da Ciência Política da época louvava a apatia como um componente importante para a estabilidade dos sistemas políticos. Lipset (1963 [1960]), em uma afirmação bastante citada, dizia que altos índices de abstenção eleitoral indicavam alta satisfação da população - as coisas iam tão bem que as pessoas julgavam desnecessária sua intervenção. De maneira um pouco mais sofisticada, Almond e Verba (1963) postulavam que a "cultura política" ideal seria aquela em que os cidadãos combinassem um elevado sentimento de sua eficácia política com raríssimas tentativas de fazê-la valer. O relatório à Comissão Trilateral insere-se na mesma lógica, apresentando-a $a$ contrario: em lugar do elogio à apatia, o temor da mobilização. Também o diferencia o tom de inquietação, enquanto as obras de Lipset e de Almond e Verba, anteriores, exalam contentamento pela situação do mundo capitalista desenvolvido e, sobretudo, dos Estados Unidos.

O modelo que Huntington e seus colegas desenvolvem tem como ponto de partida os anos de prosperidade econômica do período posterior à II Guerra Mundial, uma prosperidade que, segundo eles, foi baseada na combinação entre livre mercado e gestão keynesiana da economia, a que se somava a segurança social proporcionada pelos estados de bem-estar (CROZIER, HUNTINGTON \& WATANUKI, 1975) ${ }^{9}$. Ao mesmo tempo, foram anos de democratização generalizada, isto é, da introdução de padrões mais democráticos de relacionamento, não apenas na polis, mas também em outros espaços, como famílias e escolas (cumpre notar que as empresas permanecem de fora). A prosperidade econômica conduziu ao aumento das expectativas; a democratização, ao declínio dos padrões de deferência aos superiores sociais e do respeito às hierarquias, o que Huntington (1975, p. 102) chama de "destempero democrático”. Isso leva ao incremento das pressões sociais por melhorias localizadas. Como os políticos competem por votos, eles esforçam-se em atender essas pressões, ampliando a intervenção estatal na economia e na vida social. Como a complexidade da gestão da sociedade aumenta, há maior necessidade de controle social. Ora, esse controle é cada vez mais difícil, devido ao declínio da 9 A síntese feita nesta parágrafo acompanha Held (1996,
p. 240-244). 
hierarquia. Ao mesmo tempo, o sucesso nas pressões sobre o Estado leva a novo aumento das expectativas, portanto a mais pressões, gerando um círculo vicioso. E a ampliação da presença estatal ocasiona a redução do mercado capitalista, que seria a base da prosperidade.

Em uma palavra, "as demandas crescem, enquanto a capacidade de resposta do governo democrático está estagnada” (CROZIER, HUNTINGTON \& WATANUKI, 1975, p. 9). Não é difícil perceber as semelhanças desse modelo com outro, gerado na mesma época, mas do lado oposto do espectro político, ou seja, no marxismo e em seus arredores, que percebia uma crise fiscal e de legitimação no mundo capitalista. Tornaram-se conhecidas as análises de O’Connor (1973), de Habermas (1975 [1973]) e de outros; a melhor síntese talvez seja encontrada na elaboração de Claus Offe (1984 [1972]). Premido pela necessidade de garantir a legitimação das instituições políticas e econômicas, bem como de sua própria gestão, o governo deve conceder benefícios crescentes à maioria da população, na forma sobretudo de mecanismos de bem-estar social. Como isso é necessariamente sustentado por meio de impostos, a taxação tende a aumentar, o que compromete a outra tarefa do Estado capitalista, que é garantir a valorização do capital. Em suma, as tarefas de legitimação e de valorização do capital tendem a tornar-se contraditórias; é aí que residem os motivos da crise.

As semelhanças não escondem diferenças ainda mais importantes. Aquilo que Offe e outros autores vinculados à perspectiva marxista vêem como o conflito distributivo entre capital e trabalho, Huntington e seus parceiros descrevem como sendo as exigências exageradas de um povo malcomportado, que não percebe que, ao pôr em risco a economia de mercado, está matando a galinha dos ovos de ouro - em uma narrativa em que são claras as ressonâncias da "rebelião das massas”, de Ortega y Gasset ${ }^{10}$. A diferença fundamental, no entanto, é que, naquele momento, Offe julgava que o problema estava no capitalismo, en-

10 Nas primeiras décadas do século XX, o pensador espanhol já descrevia a erosão da hierarquia e o declínio da deferência das massas para com o reduzido grupo daqueles que tornavam possível sua prosperidade, os “seletos" (ORTEGA Y GASSET, 1987 [1937]). quanto, para os teóricos da "ingovernabilidade", o problema era a democracia.

Como as raízes da crise são o excesso de demandas e o declínio da autoridade, a solução é menos demanda e mais autoridade. Isso significa duplamente menos democracia - aliás, Huntington (1975, p. 114) afirma expressamente que há excesso de democracia e é necessário reduzi-la. Os caminhos indicados são dois, complementares. Primeiro, o reforço das hierarquias (o que se contrapõe à igualdade social, que é, como Tocqueville já observava em meados do século XIX, a matéria-prima da vida democrática), com o entendimento de que a posse de competências especiais é também um critério para a atribuição de poder, tão legítimo quanto a democracia. Segundo, o incremento da apatia política. O capítulo de Huntington, em especial, deixa claro que é necessário que certos grupos sociais permaneçam fora do processo político e chega a lamentar que os negros estadunidenses estivessem deixando sua tradicional posição de marginalizados.

De certa maneira, é possível dizer que as preocupações de Huntington e seus colegas encontraram uma solução com a implantação do projeto neoliberal (cuja desconfiança em relação à democracia nasce já nos escritos de Hayek, na primeira metade do século XX). As pressões sobre o Estado são reduzidas pela diminuição da abrangência do próprio Estado, isto é, o espaço das decisões tomadas por regras democráticas foi reduzido, ampliando-se a abrangência das decisões não-democráticas, ou de caráter mercantil (o que é sintetizado na fórmula "menos democracia, mais mercado").

Após a queda do muro de Berlim, com a rápida incorporação da antiga órbita soviética ao mundo do capitalismo liberal, ouviram-se manifestações entusiásticas apontando o triunfo definitivo das instituições ocidentais (Fukuyama) ou, ao menos, sinalizando mais uma etapa na expansão global da democracia (o próprio Huntington). Mas não tardou a acender um sinal amarelo. Se era verdade que as instituições da democracia eleitoral eram adotadas em mais e mais lugares do mundo, elas também desfrutavam de legitimidade decrescente nos próprios países centrais. Na formulação de Robert Dahl (2000), tratava-se de um "paradoxo democrático": cidadãos apegados às normas democráticas, mas descrentes das instituições que deveriam efetivá-las. 
Muitos estudos recentes buscaram mensurar e analisar esse paradoxo, destacando-se os volumes organizados por Pippa Norris e por Robert Putnam e Susan Pharr. A pesquisa dirigida por Norris apresenta-se como uma atualização de The Civic Culture - "It is The Civic Culture study 40 years later", diz a frase de Gabriel Almond reproduzida na capa -, isto é, seu foco está nas disposições políticas dos cidadãos. Já a pesquisa de Putnam e Pharr, que também foi comissionada pela Trilateral, busca dialogar com The Crisis of Democracy, tendo por interesse principal as condições de estabilidade dos sistemas políticos. Como, no modelo adotado por autores de ambos os lados, cultura política e estabilidade institucional estão intimamente relacionadas, são bastante similares não apenas os dados que apresentam (os surveys do World Values Study, aplicados em velhas e novas democracias eleitorais, são a fonte principal nos dois casos), como também a leitura que dele fazem.

Norris, expandindo categorias de David Easton, aponta cinco facetas da legitimidade política, referentes ao apoio que se expressa à comunidade política nacional, aos princípios do regime, ao desempenho do regime, às instituições do regime e aos atores políticos. Como imagem geral, é possível dizer que o nível de apoio às comunidades políticas é alto, a satisfação com o desempenho é variada e a confiança nos políticos oscila. O mais importante, porém, é o contraste entre a manutenção de índices elevados de adesão aos princípios democráticos e o declínio, em alguns casos muito acentuado, da confiança nas instituições. A autora interpreta-o como uma décalage entre a percepção de uma democracia ideal e a compreensão realista de seu funcionamento, ecoando formulações anteriores de Giovanni Sartori (1994 [1987], passim; NORRIS, 1999, p. 11). Mas é possível dizer, também, que se trata de um entendimento bastante realista quanto ao fracasso das instituições atuais em realizar promessas fundamentais da democracia, como a igualdade política entre os cidadãos e a soberania popular.

Com o foco mais restrito - a preocupação é apenas com a América do Norte, Europa Ocidental e Japão -, os estudos liderados por Pharr e Putnam observam uma onda generalizada de ceticismo ou mesmo cinismo em relação às instituições governamentais. Os dados revelariam, para uma grande maioria dos países, a queda na confi- ança popular em relação aos políticos, aos partidos e às instituições (PUTNAM, PHARR \& DALTON, 2000). Embora parte dos textos explore a questão da perda de autonomia dos governantes, com a globalização, a ênfase maior é dada a problemas na relação entre representantes e representados, em especial a deterioração da liderança política, dos padrões de julgamento dos votantes e/ou do capital social (no sentido de Putnam, isto é, o padrão de confiança interpessoal dentro da sociedade).

Assim, é possível perceber que a ativação política dos anos 1960 e 1970, que procurava distender os limites das democracias ocidentais, foi substituída por um descrédito generalizado. Talvez por trás de atitudes diferentes permaneçam sentimentos similares: há uma forte concordância quanto ao valor da democracia, na qualidade de autogoverno popular, mas os cidadãos não se sentem representados, isto é, estão enfraquecidos os laços que idealmente deveriam ligar os eleitores comuns aos parlamentares, candidatos, partidos e, de maneira mais genérica, aos poderes constitucionais. Mobilização extra-eleitoral e apatia são respostas diferentes - a primeira indica a esperança de mudança, enquanto a segunda revela ceticismo -, mas ambas opõem-se à adesão confiante no sistema político que o bom funcionamento da representação deveria disseminar.

\section{ABANDONAR A ACCOUNTABILITY?}

Os problemas da representação política nas democracias eleitorais têm levado ao surgimento de propostas inovadoras, tais como a introdução de determinado grau de aleatoriedade na escolha dos representantes ou a reserva de espaços para grupos considerados prejudicados (cotas). De maneira geral, tais propostas perseguem um ou mais dos seguintes objetivos:

(1) ampliação da representatividade mimética do corpo decisório, isto é, tornar os governantes mais parecidos com os governados;

(2) ampliação da pluralidade de vozes e perspectivas presentes nas esferas decisórias;

(3) ampliação da força política de grupos tradicionalmente marginalizados e

(4) ampliação da rotatividade nos cargos decisórios, impedindo a cristalização de uma elite política. 
Entre as críticas geralmente apontadas contra tais propostas destacam-se o possível cerceamento da liberdade do eleitor-cidadão, já que sua escolha seria limitada por critérios prévios de representatividade de determinados grupos ${ }^{11}$ ou mesmo descartada em favor de uma seleção aleatória, e a provável redução da competência dos governantes, que levaria tanto à diminuição da efetividade da ação governamental quanto à ampliação do poder das burocracias de Estado. A crítica mais importante, porém, diz respeito à redução da accountability. Na medida em que o acesso aos postos de decisão depende menos da vontade dos governados - e mais de regras prévias de distribuição das vagas entre grupos ou da sorte -, a responsividade dos governantes à vontade popular estaria seriamente comprometida.

A forma mais radical de transformação dos mecanismos representativos, que tem sido explorada por diferentes vias por teóricos políticos, é a introdução de mecanismos aleatórios para o preenchimento de cargos públicos, recuperando um procedimento próprio da democracia clássica (MIGUEL, 2000a). As múltiplas propostas de utilização de sorteio, no entanto, incluem sugestões bastante moderadas, como a "pesquisa de opinião deliberativa” de Fishkin (1989), em que uma amostra aleatória da população estuda os problemas políticos e debate-os com os candidatos, servindo de subsídio para as escolhas dos eleitores ${ }^{12}$, ou a geração de câmaras consultivas, isto é, sem poder decisório, como o "minipopulus” proposto por Robert Dahl (1989, p. 122-125; 1990, p. 340), cujo único poder efetivo seria a "influência moral” sobre a câmara eleita.

Em ordem crescente de radicalidade, temos a "votação lotérica” proposta por Amar (1984), em que cada candidato teria tantas chances de ser sorteado quanto os votos que recebeu (como for-

11 Este é o ponto destacado por Arato (2002 [2000]), em sua condenação sumária da representatividade descritiva. Outras críticas, como a relação entre a representação mimética e a "tradição dos sovietes supremos”, são descabidas. É contraditória a afirmação, no parágrafo final do artigo, de que é necessário complementar a accountability com instituições de representatividade descritiva.

12 Tentativas de implantação do que passou a chamar-se “deliberative polling TM" ("votação deliberativa”), como um empreendimento comercial-político-midiático-acadêmico, estão descritas em Fishkin (1997). ma de incentivar a participação política eleitoral); um sistema bicameral, com uma câmara legislativa eleita e outra sorteada, como a proposta de Callenbach e Phillips (1985); o complexo mecanismo da "demarquia" de Burnheim (1985), com vários órgãos decisórios formados por sorteio, cada um decidindo sobre um único tema, e, por fim, a utopia de Barbara Goodwin (1992), de uma sociedade em que todos os recursos sociais - e não apenas o poder político - são distribuídos por sorteio.

São propostas que se defrontam com três objeções básicas. A primeira - e que repercute de maneira mais intensa no senso comum - é a descrença na premissa democrática da igualdade entre todos; o sorteio deixa de lado o caráter seleti$v o$ do processo eleitoral. A segunda está ligada à idéia da eleição como autorização para que o representante aja em nome dos representados, o que a seleção aleatória não contemplaria. Em rigor, essa não é uma objeção muito séria, já que hoje se considera que a autorização é dada mesmo por aqueles que votaram nos candidatos derrotados. Ou seja, a participação no processo eleitoral significaria que há concordância quanto à justeza do processo de escolha, o que poderia valer também para o sorteio.

A terceira objeção refere-se à accountability, isto é, o fato de que os representantes são responsáveis perante seus constituintes. Ela seria eliminada se os governantes não devessem seus mandatos à vontade expressa da maioria da população, mas ao simples acaso. Seria grave a ausência da disputa eleitoral, quando os candidatos enunciam seus pontos de vista, e, sobretudo, da sanção facultada aos cidadãos, que é a possibilidade da não-recondução de seus representantes ao cargo.

Este é o ponto crucial, já que todas as propostas de reintrodução do sorteio estão ancoradas em um mesmo diagnóstico: a inoperância (ou, pelo menos, insuficiência) dos mecanismos de accountability eleitoral. A busca da eleição e da reeleição não torna os políticos especialmente sensíveis à vontade do cidadão comum mas sim à dos "grandes eleitores" - controladores de máquinas políticas locais, grupos de meios de comunicação e financiadores de campanha. Por outro lado, o papel limitado que o sistema concede ao simples cidadão, condenado a dissolver seu voto em meio a milhares ou milhões de outros, não poderia promover a participação ativa visada 
por Stuart Mill, mas apenas, como de fato ocorreu, o desinteresse e a passividade ${ }^{13}$.

Com o sorteio, o escolhido deixa de depender dos grupos poderosos, que perderiam influência política. O contra-argumento é que, sem a sanção da não-reeleição, o governante estaria muito mais exposto às tentações da corrupção e do exercício do poder em benefício próprio. A resposta, em parte, estaria em outro benefício esperado do sorteio: o rodízio de cidadãos nos cargos de governo. Um dos problemas relacionados à democracia representativa é precisamente o fato de que os representantes, ao especializarem-se nessa função, desenvolvem interesses particulares, diferentes daqueles de seus constituintes - o fenômeno que, há 90 anos, Robert Michels chamou, com exagero retórico, de "a lei de ferro da oligarquia". Com a escolha ao azar, deixa de existir o político profissional. Cada mandato será, provavelmente, o único daquele indivíduo. Ou seja, seu interesse a médio e longo prazos não é o interesse do governante, mas do governado que em breve voltará a ser. Esse era um elemento não-desprezível na arquitetura da polis grega.

Com esse rodízio nas funções públicas, aumentaria em muito o número daqueles que teriam alguma experiência de governo. Cada cidadão ou cidadã já teria cumprido um mandato ou estaria na expectativa de cumpri-lo. No seu ambiente de moradia e de trabalho, encontraria muitos outros na mesma situação. Isso geraria o interesse e a qualificação políticas, que se contrapõem à apatia e à passividade próprias dos regimes eleitorais.

Uma última vantagem da seleção aleatória é a garantia de representatividade (no sentido mimético) da população. Com base na lei dos grandes números, é possível afirmar que haverá uma proporcionalidade aproximada dos diferentes setores no corpo governante. A busca de uma proporcionalidade mais estrita, com a aplicação

13 Pelo menos desde os anos 1940, com os trabalhos de Schumpeter e Lazarsfeld, há o reconhecimento da indiferença "típica” do eleitor comum. A interpretação dada ao fato varia: é um efeito da "natureza humana”, um componente necessário à estabilidade do sistema político (que, de outra forma, seria excessivamente tensionado) ou, em uma leitura mais crítica, a conseqüência de certos vieses estruturais desse mesmo sistema. Para duas diferentes abordagens dessa última corrente, ver Bourdieu (1979, cap. 8) e Offe (1984 [1972]). de técnicas de amostragem, coloca problemas graves - idênticos aos das cotas - já que teriam que ser definidas a priori tanto as clivagens sociais relevantes quanto a alocação de cada indivíduo dentro dos grupos.

De todas as propostas de transformação dos mecanismos de seleção de representantes, o sorteio é a que avança de forma mais decidida em direção a quatro dos objetivos citados acima, embora ao custo de maiores perdas de autoridade para a população comum. Propostas envolvendo cotas têm impacto pequeno, embora não nulo, no quarto objetivo (ampliação da rotatividade entre governantes e governados). Ao contrário da seleção aleatória, que levaria à melhoria da representatividade mimética dos corpos decisórios, mas cujo procedimento inicial é a atomização dos cidadãos, as cotas estão ligadas à idéia de representação de grupos.

Um dos principais problemas identificados na representação política contemporânea diz respeito à sub-representação de determinados grupos sociais. O grupo dos governantes, em relação ao conjunto da população, tende a ser muito mais masculino, muito mais rico, muito mais instruído e muito mais branco - uma observação que vale para o Brasil e para as democracias eleitorais em geral. A expansão da franquia eleitoral, com a incorporação de novos grupos, como as mulheres, os trabalhadores e os analfabetos à cidadania política, não modificou de maneira substantiva a situação. Como observou Anne Phillips (1999, p. 35), não basta eliminar as barreiras à inclusão, como no modelo liberal: é necessário incorporar explicitamente os grupos marginalizados ao corpo político.

A afirmação da relevância política dos grupos sociais leva a uma ruptura com o individualismo abstrato que marca o pensamento liberal (e, por intermédio dele, o ordenamento constitucional das democracias ocidentais). O rompimento com essa tradição é embasado teoricamente por uma miríade de pensadores, que, no entanto, oscilam desde a exaltação à diferença de grupo, com o abandono de qualquer perspectiva unificadora, como Iris Marion Young (1990), até a busca de um compromisso com o republicanismo cívico, enfatizando a necessidade de que as pessoas percebam os limites de sua própria posição diante "da comunidade mais ampla à qual todos em última análise pertencemos”, que é a posição da própria Phillips (1993, p. 106).

O principal mecanismo da promoção da parti- 
cipação política de grupos subordinados é a adoção de cotas eleitorais (MIGUEL, 2000b; 2001). Embora por vezes elas sejam adotadas para proteger minorias étnicas, em especial grupos indígenas, a maior parte das experiências de cotas eleitorais beneficia as mulheres (como acontece no Brasil), que passam a ter uma reserva de cadeiras no parlamento ou de candidaturas às eleições. A efetividade da medida - isto é, o aumento real da presença feminina nos fóruns decisórios é influenciada por diversos fatores, notadamente o sistema eleitoral ${ }^{14}$.

Há uma clara ligação entre essa perspectiva e aquilo que, em seu estudo hoje clássico, Hanna Pitkin (1967) descreveu (e criticou) como "representação descritiva”, que concebe o parlamento como uma espécie de mapa, no qual se vê a imagem perfeita, embora em tamanho reduzido, da sociedade. Com isso, o que os representantes $f a-$ zem perde importância em relação a quem eles são e um aspecto valioso da representação política, a responsividade dos eleitos para com seus eleitores, é deixado de lado.

Ao defender o que prefere chamar de "política de presença” das críticas de Pitkin e outros, Anne Phillips (1995) admite que ela nasce da desilusão com a accountability vertical, que se mostrou incapaz de proteger as minorias. No entanto, cumpre ressaltar que a ruptura promovida pela adoção de cotas é muitas vezes menos drástica do que a da seleção lotérica. A reserva de vagas para integrantes de determinados grupos sociais não exclui a necessidade de que todos os representantes passem pelo processo eleitoral, respondendo aos cidadãos comuns.

\section{CONCLUSÕES}

Tanto as propostas de seleção aleatória dos governantes quanto as de reserva de vagas para grupos marginalizados revelam descontentamento com o funcionamento dos mecanismos de accountability vertical. As sanções de que os constituintes dispõem - e que se resumem, para todos os efeitos, ao poder de retirar ou manter os representantes em seus cargos a cada eleição - parecem insuficientes para garantir a responsividade de suas

14 Para discussões sobre os efeitos no Brasil e comparações com outros países, ver S. M. Miguel (2000) e também Araújo (1998; 2001). decisões. A representatividade mimética surge como uma aposta para prover responsividade sem necessidade de accountability; em seu lugar, entra a similitude. As decisões políticas poderiam corresponder à vontade dos cidadãos comuns porque seriam tomadas por pessoas similares a eles ${ }^{15}$.

No caso das cotas, a similitude é um complemento à accountability - os representantes continuam dependentes do voto popular, mas os interesses de determinados grupos serão levados em conta graças à presença de um contingente de seus integrantes nos espaços decisórios. No extremo, a accountability realizar-se-ia exclusivamente entre semelhantes, como se depreende da proposta de Iris Marion Young (1990, p. 184-187) de conceder poder de veto aos representantes das minorias, naquelas questões que as afetam ${ }^{16}$.

Já o sorteio, por sua lógica intrínseca, leva ao abandono completo da accountability vertical, que é então substituída (e não apenas complementada) pela similitude. Talvez por isso, quase todas as propostas de introdução de loterias nas democracias contemporâneas combinam-nas com processos eleitorais, de modo a não eliminar de vez alguma forma de controle popular sobre os representantes. Cabe ressaltar que o sorteio reforça a similitude, na medida em que promove a rotação nos cargos públicos. Isto é, quem exerce o poder decisório sabe que em breve voltará à condição de cidadão comum; a posição de governante, sendo transitória, não criaria interesses duradouros, diferenciados de sua posição enquanto integrante do povo.

Do ponto de vista prático, no entanto, essa continua sendo a objeção mais forte contra a aposta na similitude. Sem os freios e incentivos que oferece a possibilidade de imposição de sanções, tanto positivas quanto negativas, pelo povo comum, os detentores do poder decisório dificilmente resistiriam à tentação de prover seu benefício particular, legislando em causa própria ou, então, cedendo à corrupção. $\mathrm{O}$ resultado seria ou o

\footnotetext{
15 O formalismo de boa parte da teoria democrática convencional tende a desprezar esse tipo de afirmação, que, no entanto, já estava bem presente (de diferentes maneiras) em pensadores sensíveis aos determinantes sociais da política, como Rousseau ou Tocqueville.

16 Em obra posterior (YOUNG, 2000), a autora recuou da proposta.
} 
descalabro ou o inchamento dos organismos de controle, isto é, o reforço da accountability horizontal a expensas da vertical. De um jeito ou de outro, é reduzida a soberania popular.

Do ponto de vista teórico, há outro problema grave. Quando a vida política é pensada apenas em termos da promoção de interesses, como em geral ocorre, fórmulas que visam a garantir a presença de determinados grupos nas esferas de poder perdem força. Afinal, os eleitores manifestam seu interesse por meio do voto. Se cada um é o melhor juiz de seu próprio interesse, como quer o dogma utilitarista, então os grupos hoje marginalizados elegeriam seus integrantes para os cargos decisórios, sem necessidade de medida alguma além da mera igualdade política formal, caso isso fosse realmente a sua vontade. Por outro lado, se os indivíduos estão submersos na "falsa consciência” e encontram obstáculos para a identificação de seus interesses verdadeiros, tais fenômenos de alienação continuariam presentes, independentemente do acesso de tais ou quais pessoas ao poder.

Nesse sentido, é interessante o deslocamento proposto por Young (2000), que fala em "perspectiva social" em vez de "interesse". O acesso de integrantes de grupos marginalizados às deliberações públicas é necessário não porque eles compartilhem das mesmas opiniões ou interesses, mas porque partem de uma mesma perspectiva social, ou seja, um local de onde se vê o mundo, vinculado a certos padrões, socialmente estruturados, de experiências de vida. A palavra é significativa: trata-se de um ponto de partida, não de chegada. A idéia de perspectiva permite captar a sensibilidade da experiência formada pela posição do grupo, sem postular um conteúdo unificado (idem, p. 138-139). As mulheres, por exemplo, podem conceber de diferentes maneiras seus interesses - e esses interesses podem muito bem ser defendidos por homens. Mas elas trazem para a arena pública determinadas vivências comuns, vinculadas à posição subordinada que hoje ocupam nos diferentes espaços sociais, que dão forma a uma perspectiva que nenhum homem, por mais sensível que seja aos problemas femininos, é capaz de incorporar.

Young está ligada a uma visão algo habermasiana de "democracia deliberativa", que busca um ideal de diálogo desprendido e voltado para o consenso, cedendo pouco espaço à noção de interesse. Ainda assim, sua abordagem é importante, pois mostra que a necessidade da presença das minorias na arena política não é suprimida caso encontrem-se outras formas de proteger seus "interesses", qualquer que seja a forma por que eles sejam concebidos.

Rousseau (1964 [1757], p. 429), em sua famosa condenação à representação política, afirmava que não se pode representar a soberania, pois ela consiste essencialmente na vontade (geral) e "a vontade absolutamente não se representa”. É razoável dizer que a perspectiva também não se representa - no máximo, é compartilhada. O que não significa que ela esgote o problema do exercício do poder nas sociedades contemporâneas. Prosseguindo com Iris Marion Young (2000, p. 134-136), ela observa que a representação envolve tanto interesses (aquilo que se considera necessário para que agentes individuais ou coletivos alcancem seus fins) e opiniões (valores e princípios que fundam os julgamentos) quanto perspectivas.

Mecanismos representativos adequados devem envolver essas três facetas. Para o bom funcionamento da accountability vertical, que exige formas de empowerment dos cidadãos comuns, é imprescindível para que interesses e opiniões dos diferentes grupos sociais estejam presentes nas esferas decisórias; mas as perspectivas não são contempladas dessa maneira. Elas demandam presença política; se integrantes dos diversos grupos não participam do debate, os aspectos da realidade aos quais eles tornaram-se sensíveis, com base em suas experiências de vida, não serão levados em consideração.

Instrumentos que promovam a responsividade de modo independente da accountability podem ser importantes para garantir a presença das diferentes perspectivas sociais nos locais de discussão e decisão política. É o que justifica a adoção de cotas eleitorais, medida que o individualismo liberal é incapaz de assimilar. As propostas de sorteio padecem de contra-indicações mais sérias; suas fragilidades são bastante evidentes e, de maneira geral, parecem inviáveis para implementação efetiva, salvo, talvez, em nível local. Mas elas incorporam críticas importantes, que merecem ser levadas em consideração, a respeito do funcionamento da representação eleitoral e, em particular, da accountability. 
Luís Felipe Miguel (lfelipe@unb.br) é Doutor em Ciências Sociais pela Universidade Estadual de Campinas (Unicamp) e Professor do Instituto de Ciência Política da Universidade de Brasília (UnB).

\section{REFERÊNCIAS BIBLIOGRÁFICAS}

AFONSO, J. R. R. 1999. Brasil : descentralización y accountability del gobierno local. Artigo apresentado na $5^{\text {th }}$ Annual Conference on Development in Latin America and the Caribbean, realizada em Valdivia (Chile) sob os auspícios do Banco Mundial. Digit.

ALMOND, G. A. \& VERBA, S. 1963. The Civic Culture: Political Attitudes and Democracy in Five Nations. Princeton : Princeton University.

AMAR, A. R. 1984. Choosing Representatives by Lottery Voting. Yale Law Journal, New Haven, v. 93, n. 7, p. 1283-1308, June.

ARATO, A. 2002 (2000). Representação e accountability. Lua Nova, São Paulo, n. 55-6, p. 85-103.

ARAÚJO, C. 1998. Mulheres e representação política : a experiência das cotas no Brasil. Estudos Feministas, Rio de Janeiro, v. 6, n. 1, p. 71-90, jan.-jun.

2001. As cotas por sexo para a competição legislativa : o caso brasileiro em comparação com experiências internacionais. Dados, Rio de Janeiro, v. 44, n. 1, p. 155-194.

BAGDIKIAN, B. 1997. The Media Monopoly. Boston : Beacon.

BOURDIEU, P. 1979. La distinction : critique sociale du jugement. Paris : Minuit.

BURKE, E. 1942 (1774). Discurso a los electores de Bristol. In : Textos políticos. Ciudad de México : Fondo de Cultura Económica.

BURNHEIM, J. 1985. Is Democracy Possible? The Alternative to Electoral Politics. Berkeley : University of California.

CALLENBACH, E. \& PHILLIPS, M. 1985. A Citizen Legislature. Berkeley : Banyan Tree.

CROZIER, M. J.; HUNTINGTON, S. P. \& WATANUKI, J. 1975. The Crisis of Democracy: Report on the Governability of Democracies to the Trilateral Commission. New York : New York University.
DAHL, R. A. 1989. Democracy and its Critics. New Haven : Yale University.

1990. After the Revolution? Authority in a Good Society. Revised edition. New Haven : Yale University.

2000. A democratic paradox? Political Science Quaterly, Washington, D. C., v. CXV, n. 1, p. 35-40, Spring.

DOWNS, A. 1957. An Economic Theory of Democracy. New York : Harper.

FISHKIN, J. S. 1989. Democracy and Deliberation : New Directions for Democratic Reform. New Haven : Yale University.

1997. The Voice of the People : Public Opinion and Democracy. New Haven : Yale University.

GOODWIN, B. 1992. Justice by Lottery. Chicago : The University of Chicago.

GRAMSCI, A. 2000 (1932-1934). Cadernos do cárcere. V. 3: Maquiavel. Notas sobre o Estado e a política. Rio de Janeiro : Civilização Brasileira.

HABERMAS, J. 1975 (1973). Problemas de legitimación en el capitalismo tardío. Buenos Aires : Amorrortu.

HELD, D. 1996. Models of Democracy. Stanford : Stanford University.

HUNTINGTON, S. P. 1975 (1968). A ordem política nas sociedades em mudança. Rio de Janeiro : Forense-Universitária.

. 1975. The United States. In : CROZIER, M. J.; HUNTINGTON, S. P. \& WATANUKI, J. The Crisis of Democracy : Report on the Governability of Democracies to the Trilateral Commission. New York : New York University.

LIPSET, S. M. 1963 (1960). Political Man : The Social Bases of Politics. Garden City : Anchor.

MANIN, B. 1997. The Principles of Representative Government. Cambridge : Cambridge University. 
MANIN, B.; PRZEWORSKI, A. \& STOKES, S. C. 1999. Introduction. In : (eds.). Democracy, Accountability, and Representation. Cambridge : Cambridge University.

MCCHESNEY, R. W. 1999. Rich Media, Poor Democracy : Communication Politics In Dubious Times. Urbana : University of Illinois.

MICHELS, R. 1982 (1914). Sociologia dos partidos políticos. Brasília : UNB.

MIGUEL, L. F. 2000a. Sorteios e representação democrática. Lua Nova, São Paulo, n. 50, p. 69-96.

2000b. Teoria política feminista e liberalismo : o caso das cotas de representação. Revista Brasileira de Ciências Sociais, São Paulo, v. 15, n. 44, p. 91-102, out.

2001. Política de interesses, política do desvelo : representação e "singularidade feminina”. Estudos Feministas, Florianópolis, v. 9, n. 1, p. 253-267, jan.-jun.

2003. Representação política em 3-D : elementos para uma teoria ampliada da representação política. Revista Brasileira de Ciências Sociais, São Paulo, v. 18, n. 51, p. 123-140.

MIGUEL, S. M. 2000. A política de cotas por sexo : um estudo das primeiras experiências no legislativo brasileiro. Brasília : Centro Feminista de Estudos e Assessoria.

MONTESQUIEU. 1951 (1748). De l'esprit des lois. In : . Euvres complètes. T. II. Paris : Gallimard.

NORRIS, P. 1999. Introduction : The Growth of Critical Citizens? In : (ed.). Critical Citizens : Global Support for Democratic Governance. Oxford : Oxford University.

O’CONNOR, J. 1973. The Fiscal Crisis of State. New York : St. Martin.

OFFE, C. 1984 (1972). Dominação de classe e sistema político : sobre a seletividade das instituições políticas. In : Problemas estruturais do Estado capitalista. Rio de Janeiro : Tempo Brasileiro.

ORTEGA Y GASSET, J. 1987 (1937). A rebelião das massas. São Paulo : M. Fontes.
PATEMAN, C. 1985. The Problem of Political Obligation : A Critique of Liberal Theory. Berkeley : University of California.

PERUZZOTTI, E. \& SMULOVITZ, C. 2001. Accountability social : la otra cara del control. In : PERUZZOTTI, E. \& SMULOVITZ, C. (orgs.). Controlando la política : ciudadanos $\mathrm{y}$ medios en las nuevas democracias latinoamericanas. Buenos Aires : Temas.

PHILLIPS, A. 1993. Must Feminists Give Up on Liberal Democracy? In : HELD, D. (ed.). Prospects for Democracy : North, South, East, West. Stanford : Stanford University.

1995. The Politics of Presence. Oxford : Oxford University.

1999. Which Equalities Matter? Cambridge : Polity.

PITKIN, H. F. 1967. The Concept of Representation. Berkeley : University of California.

PUTNAM, R. D.; PHARR, S. J. \& DALTON, R. J. 2000. Introduction : What's Troubling the Trilateral Democracies? In : PHARR, S. J. \& PUTNAM, R. D. (eds.). Disaffected Democracies : What's Troubling the Trilateral Countries? Princeton : Princeton University.

ROUSSEAU, J.-J. 1964 (1757). Du contrat social. In : ris : Gallimard.

SARTORI, G. 1994 (1987). A teoria da democracia revisitada. 2 v. São Paulo : Ática.

SHAH, A. s/d. Fostering Responsible and Accountable Governance : Lessons from Decentralization Experience. Disponível em : http://www.federativo.bndes.gov.br/. Acesso em : jul.2003.

YOUNG, I. M. 1990. Justice and the Politics of Difference. Princeton : Princeton University.

2000. Inclusion and Democracy. Oxford : Oxford University.

WORLD BANK. 1999. Fostering Institutions to Contain Corruption. PremNotes, n. 24. Washington, D. C. : The World Bank Group. Disponível em: http://www.worldbank.org/. Acesso em : jun.2003. 